\title{
MACRO AND Micro CHALLENGES FOR TALENT RETENTION IN SOUTH Africa
}

\section{Authors:}

Berenice Kerr-Phillips ${ }^{1}$

Adèle Thomas ${ }^{2}$

\section{Affiliations:}

${ }^{1}$ Department of Industrial

Psychology and People

Management, University of

Johannesburg, South Africa

${ }^{2}$ Department of Business

Management, University of

Johannesburg, South Africa

Correspondence to:

Adèle Thomas

e-mail:

adelet@uj.ac.za

\section{Postal address:}

Department of Business

Management, University of

Johannesburg, PO Box 524,

Auckland Park 2006,

South Africa

\section{Keywords:}

New Zealand; achievers;

talent attrition; leadership; emigration

\section{Dates:}

Received: 30 July 2008

Accepted: 25 May 2009

Published: 17 July 2009

How to cite this article:

Kerr-Phillips, B., \&

Thomas, A. (2009). Macro

and micro challenges

for talent retention in

South Africa. SA Journal

of Human Resource

Mangement/SA Tydskrif vir

Menslikehulpbronbestuur, 7(1),

Art. \#157, 10 pages. DOI:

10.4102/sajhrm.v7i1.157

This article is available

at:

http://www.sajhrm.co.za

(C) 2009. The Authors. Licensee: OpenJournals

Publishing. This work

is licensed under the

Creative Commons

Attribution License

\section{ABSTRACT}

The aim of the study was to explore the challenges presented in retaining South Africa's talent at both macro (country) and micro (organisational) levels. Using a web-based survey placed on eight New Zealand sites, the reasons for emigration of South African talent during the period 1994-2006 were explored with 84 respondents. Utilising a purposive sampling technique, 20 semi-structured interviews were undertaken with identified 'top talent' in two financial services companies. Content analysis of the responses from both samples was employed. Reasons for emigration (macro issues) included uncertainty about the future of the country, job insecurity and fears regarding both corruption and violent crime. Reasons for talent loss amongst identified top talent (micro issues) were found to be linked to leadership, organisational culture and employment equity.

\section{Key focus of the study}

\section{INTRODUCTION}

In the light of current skills shortages and the impact that this has on competitiveness, the present study focuses on the reasons for the emigration of talented South Africans as well as on the reasons why talent at senior levels in South African organisations may choose to leave their companies of employ. By identifying reasons for emigration as well as those reasons contributing to senior talent attrition in South African companies, recommendations are furnished to address this loss at both country and individual company levels.

\section{Background to the study}

It is imperative that South Africa becomes globally competitive. The World Competitiveness Report (IMD, 2008) lists South Africa in 53rd position in a ranking of the competitiveness of 55 nations, a decline from previous years. A critical component of competitiveness is having the appropriate skills complement across a range of occupations and professions as well as the skills to drive leadership in South African organisations. Pfeffer (1994) notes that those organisations that are intent on becoming competitive must necessarily rely on talented and dedicated employees. In a report for McKinsey and Company, Guthridge, Komm and Lawson (2008), however, reveal that while internationally, skills shortages and the 'war for talent' are recognised as critically impacting competitiveness, few companies integrate clear strategies for talent acquisition and retention into their mainstream business strategies.

As is evident in other developing countries, South Africa is currently experiencing a brain drain that could severely impact its competitiveness (Du Preez, 2002). Paton (2003, p. 18) notes in this regard that 'government's ambition to grow [the] manufacturing base risks being stillborn unless the country addresses a worsening skills crisis.' Behar (2006) illustrates how the development and retention of skilled people in a country contributes to country growth and benefits all occupations, including the unskilled ones. Behar (2006) further notes that the belief that skills shortages constrain economic growth in South Africa motivated the government to introduce the Joint Initiative on Priority Skills Acquisition (JIPSA) in 2006 and the associated Accelerated and Shared Growth Initiative for South Africa (ASGISA) in order to identify urgent skills requirements and to develop effective solutions to address these requirements. Contogiannis $(2007$, p. 44) stresses that 'skills shortages in the South African economy, and the reasons behind them, are well known and they are one of the major constraints for a sustainable economic growth.' In addition to the macro skills shortage, strong competition exists in the country amongst companies to attract the best remaining talent (Mitchell, Holtom \& Lee, 2001). Accordingly, a key macro challenge for South Africa is to retain its talent in the country. Similarly, at micro level, the challenge exists for companies to retain the existing senior talent who can contribute to organisational competitiveness.

\section{Trends from the research literature}

The South African brain drain

South Africa is experiencing a general skills crisis, especially pertaining to the retention of its top talent or 'knowledge workers'. This 'brain drain' leads to the depletion or loss of intellectual and technical personnel, with a negative outcome that impacts the economic and social growth of the country (Du Preez, 2002). Internationally, Clarke (2001) reports on the critical labour and skills shortages in virtually all industries and Lengahan and Eisner (2006) stress that global unemployment rates and associated job mobility will not resolve the shortage of top talent. For organisations, the retention of skills is the only viable option.

In South Africa there have been three peaks in emigration: in 1977 (after the Soweto riots); in 1986 (during the States of Emergency); and in 1994 (during the introduction of the ANC government) (Simelane, 1999). The past ten years have witnessed a dramatic increase in the emigration of South Africans to countries such as Australia, New Zealand and the United Kingdom (Statistics South Africa, 
2005). With figures indicating that during 1997-2001 South Africa lost an estimated 310000 citizens, including 50000 professionals, South Africa is undoubtedly experiencing a skills crisis (Crush, 2002) that is unlikely to slow down in the foreseeable future (Mattes \& Richmond, cited in Crush, 2002). Statistics South Africa (2005) reports that there was a further increase in the emigration of South Africa's skilled workforce between the years 2002-2003, of which $65 \%$ were economically active and $26.7 \%$ were professionals, and that the United Kingdom, Australia, New Zealand, Canada and the United States have emerged as the emigration destinations of choice.

With regard to emigration to New Zealand, specifically during 2006-2007, South Africans constituted the second largest source of skilled migrants, involving the contribution of 3201 skilled workers or business people to the New Zealand economy, with South Africa comprising, again, the second largest source of skilled or business applicants to that country (Merwood, 2008). Further, South Africa was one of the main source countries contributing 'talented' employees to New Zealand through the Talent (Accredited Employers) Policy in 2006-2007 (Merwood, 2008). The trend of migration of South Africans to New Zealand is increasing, as indicated by 1000 work permits being granted by New Zealand to South Africans in 1997-1998, rising to 3985 work permits being granted in 2006-2007 (Merwood, 2008). The fact that South Africans score highest on the Skilled/Business Stream assessment test amongst the top 12 countries (Merwood, 2008) indicates that it is talented South Africans who are emigrating to New Zealand.

In addition, the official emigration statistics, when compared to immigration figures received from other countries, appear to understate the problem (Du Preez, 2002). In contrast to the loss of skilled and talented South Africans, of the number of economically active immigrants who arrived in South Africa during 2002-2003, only $4.7 \%$ were professionals and 3.9\% were managers. Unskilled immigrants place a strain on the economy and potentially increase crime levels due to their limited means of income generation and limited ability to obtain skilled jobs (Mitchell, 2003). South Africa's brain drain of economically active and professional people, with no increase in skilled immigrants, negatively impacts South Africa's ability to compete effectively in a global marketplace (Du Preez, 2002). Accordingly, it is imperative that South Africa retains its knowledge workers in order to promote its global competitiveness (Denton \& Vloeberghs, 2003), noted above to have dropped in recent years (IMD, 2008).

\section{Challenges for companies presented by the macro environment}

The sustainability of the South African marketplace has been impacted by the country's own political, economic and social history. Prior to 1994, apartheid laws restricted the progress of black employees in the workplace (Finestone \& Snyman, 2005). Empowerment policies have been legislated to address these imbalances and to grow the economy by facilitating the introduction of previously marginalised people (Horwitz, 1996). The Employment Equity Act (Republic of South Africa, 1998) introduced affirmative action measures to ensure the equitable representation and advancement of designated groups (Africans, Coloureds, Indians, women and people with disabilities) in the workplace. The Broad-based Black Economic Empowerment Act (Republic of South Africa, 2003) followed, with the purpose of increasing the participation of black ownership of major industrial companies (Jackson, Alessandri \& Black, 2005). Companies are required to manage the implementation of this labour legislation and compete internationally whilst protecting their local markets from international competitors (Denton \& Vloeberghs, 2003).

\section{Internal challenges for South African companies}

While retaining talent in the country is a macro challenge for
South Africa, South African companies also face the micro challenge of retaining top talent in their own organisations. It is these knowledge workers who, through their intellectual capital control the competitive advantage of the organisation (Birt, Wallis \& Winternitz, 2004). Mitchell, Holtom and Lee (2001) note that managers face a constant challenge to develop and retain talent and to curb the impact of market-driven turnover amongst this talent group by dominating the war for talent in local and global contexts.

Many reasons for the turnover of employees have been advanced in the literature: Kim, Price, Mueller and Watson (1996) have linked employee turnover to individual characteristics, workplace structures and environmental conditions. Mueller, Boyer, Price and Iverson (1994); Griffeth, Hom and Gaertner (2000); and Mallol, Holtom and Lee (2007) stress how, given alternatives, employees tend to remain with their organisations of employment if they experience job satisfaction and are committed to their organisations or leave if they are not. Lum, Kervin, Clark, Reid and Sirola (1998) earlier found that job satisfaction has only an indirect influence on the intention to quit while organisational commitment has the most direct impact. Iverson and Roy (1994) found a link between intention to leave a workplace and remuneration and career opportunities. Schaufeli and Enzmann (1998) note how conflict with colleagues and/or with supervisors may lead to resignations while Houkes, Janssen, De Jonge and Bakker (2003) identify a complex relationship between intention to resign and unmet career expectations. LunaArocas and Camps (2008) suggest a link between job enrichment strategies, employee commitment and turnover intentions and Elangovan (2001) details the complex influence of causal events such as stress, job satisfaction and work commitment on the final decision to leave. Glen (2006) notes that the retention of knowledge workers and their specialised skills is critical for the advancement of an organisation's intellectual capital base.

In addition to the challenges faced in retaining talent, South African business leaders have had to acquire the skills to effectively manage postapartheid organisational culture and business dynamics (Luthans, Van Wyk \& Walumbwa, 2004), including the management of the broad range of diversity brought into organisations by the new demographic employee pool (Thomas \& Jain, 2004). Accordingly, ethnic and language diversity, affirmative action and the gaps in income levels, education and opportunities influence the complexity of organisational culture in the South African workplace (Roodt, 1997). South African business leaders, therefore, are required to develop skills to effectively manage a multicultural and ethnic workplace, historically dominated by Eurocentric, autocratic and hierarchical conglomerates (Prime, 1999) and based on Western value systems that are often individualistic, self-centred, competitive and exclusive (Finestone \& Snyman, 2005). In this regard, Prime (1999) notes that not all groups in an organisation share a vision for the competitiveness that can be achieved from diversity and that knowledge sharing among diverse employees is often 'sporadic' and difficult.

In managing such diversity, leaders are challenged to create organisational cultures in which the mix of diverse individuals is harnessed for competitive advantage (Thomas, 2002; Thomas \& Jain, 2004). South African organisations must ensure that organisational cultures are inclusive of all and encourage the full participation of all the diverse employees who now comprise the workforce (Thomas \& Doak, 2000), particularly top talent who can drive and advance the intellectual capital of the organisation.

In order to prepare South Africa's future leaders to be successful in this dynamic work environment, current business leaders must serve as role models. This involves the active coaching and mentoring of top talent, ensuring that they have a belief in organisational change and an appreciation of the advantages of workplace diversity (Gbadamosi, 2003). This is of particular 
importance given the underlying culture of mistrust and reluctance to share information that many South African organisations display (Thomas \& Jain, 2004) due to the opposing challenges of historical past exclusionary workplace practices and current compliance with affirmative action (Denton \& Vloeberghs, 2003).

\section{Research objectives}

The aim of the present study was to highlight the challenges of retaining South Africa's talent at both macro (country) and micro (organisational) levels. The objectives were, therefore, to identify the key macro factors that push South Africa's talent to leave the country as well as the key micro factors that could assist South African organisations in retaining their top talent to ensure the overall sustainability of such organisations in a global marketplace. The overall research question that guided the study was, What macro and micro factors impact on the retention of South African talent?

\section{The potential value-add of the study}

The findings of the present study may inform, on a practical basis, macro strategies to retain South Africa's talent as well as provide business leaders with insight into strategies that can be used to retain the top talent that remains in the country, currently employed in South African organisations.

\section{What will follow}

The paper discusses the research design employed in the present study. This includes a description of the research approach and the populations and samples that were studied in order to address both macro reasons for emigration and organisational reasons for top talent attrition. The development of the measuring instruments is considered along with the research process followed to collect and analyse the qualitative data. The findings are then presented. The paper concludes with a discussion of the findings and recommendations to guide strategies to stem the flow of emigration of talented South Africans as well as strategies that leaders can consider in retaining talented individuals in senior positions in South African organisations.

\section{Research approach}

RESEARCH DESIGN

The present study utilised both survey and qualitative semistructured interview approaches. The first part of the study involved the establishment of a web-based survey to identify the main push forces that have caused South Africans to emigrate to New Zealand, with particular focus on key triggers for such emigration (Oberoi \& Lin, 2006). The second part of the study involved conducting 20 semi-structured interviews with employees identified as top talent in two South African financial institutions, that is those employees who were designated by companies for top leadership positions. The method of semi-structured interviews was chosen as it incorporates the qualitative discussion element of strategic conversations whilst using a framework of standard questions that are prepared in advance (Ratcliffe, 2002), maximising opportunities for collecting meaningful information and allowing for the probing of complex issues.

\section{Research strategy}

The web survey population comprised all South Africans who emigrated to New Zealand between 1994 and 2006. New Zealand was selected due to it being identified by Statistics South Africa (2005) as one of the main countries to which South Africans emigrate. Furthermore, New Zealand was chosen due to its relatively small population size, which potentially allowed a more specific expatriate sample to be drawn upon. The date range of 1994-2006 was chosen in order to determine whether there is a positive link between macro social, economic and political events that have taken place in South Africa during that time and emigration. Given that South Africans comprise the second greatest source of skilled or business migrants to New Zealand and score highest on the assessment test for skilled/ business migrants (Merwood, 2008), it can be argued that the target population were skilled and talented former South Africans.

For the purposes of understanding the factors that lead to top talent attrition, all companies in South Africa were considered to comprise the research population. A purposive sample of two leading companies in the South African financial sector was chosen, this sector being considered to play a key role in the global marketplace.

\section{Research method \\ Research setting}

Two research settings were utilised: eight New Zealand websites were the source for the web-based survey; two financial institutions comprised the research setting for the qualitative interviews with identified top talent.

\section{Entrée and establishing researcher roles}

To initiate the web survey, a number of websites that are hosted by expatriate South Africans living in New Zealand were targeted. The web hosts responsible for each website were approached via e-mail and were provided with the rationale for the study. They were asked to provide an accurate estimate of the average number of subscribers and the number of 'hits' that their specific website receives to allow the researchers to gain insight into the potential number of survey respondents from each particular site. Based on this information, the web hosts of each of the eight popular websites were utilised. Upon accessing the web survey, respondents were provided with additional information relating to the purpose of the survey and were given the assurance of anonymity and confidentiality due to the nature of the data capturing. An e-mail address was also provided and respondents were encouraged to seek additional information should they require it. Once the survey results had been analysed, the relevant web hosts were notified by e-mail of the findings in compliance with the recommendation of Fox, Murray and Warm (2003) to adhere to this ethical practice.

With regard to the interviews at each of the two financial institutions, the researchers notified the selected interviewees via a standardised e-mail that outlined the purpose of the research, the nature of the questions and the interview process. Potential interviewees were informed that participation in the study was voluntary. An e-mail address was included to afford potential respondents an opportunity to pose questions before they committed to the interview, allowing them to elect not to participate if they so desired. The researchers reinforced the confidentiality of all responses (Gubrium \& Holstein, 1997).

\section{Sampling}

The eight New Zealand web hosts opened the survey for a sixweek period in 2007 and expatriate South Africans employed in New Zealand were encouraged to complete the survey. In response to these advertisements, 84 respondents completed the web survey, 37 being female and 48 male. $93 \%$ of the sample (78 respondents) were white; $5 \%$ (four respondents) were coloured; $1 \%$ (one respondent) was African; and 1\% (one respondent) was Indian. The generic, collective term 'black' is used when referring to African, Coloured and Indian web respondents or company interviewees.

In each financial institution, the sampling frame included all permanent staff members who were formally targeted as having the potential to be in top leadership positions, that is currently positioned at the level below directorship. The combined list of top talented employees from both companies comprised 79 names. From each separate company list, ten participants were 
randomly selected. Both groups of interviewees consisted of men and women from previously advantaged groups (white interviewees) as well as previously disadvantaged backgrounds (black interviewees). Of the 20 interviewees, nine interviewees were white males, eight were white females, one was an African female and two were Indian males. The sectors that the interviewees represented in both organisations included strategic project management, commercial property, capital management, housing development, information technology, enterprise risk management, insurance, diversity management, human resources and business development.

\section{Data collection methods}

Once the web-based survey was ready to be launched, each of the selected web hosts was e-mailed a standardised message advertising the survey and the website link. The survey was designed to capture frequencies of responses along with qualitative input from respondents who completed the questionnaire on eight websites. The web survey questions were structured to ascertain the occupational and income levels of the participants and the previous roles that participants played in the South African working environment. In order to facilitate the exploration of reasons for company top talent attrition, one of the researchers personally undertook all 20 semi-structured interviews at the two financial institutions.

\section{Recording of data}

The web survey primarily consisted of single-response questions (refer to Appendix 1). Where open-ended questions were posed, a commentary box was provided to ensure that the respondent could add an explanation. Respondents were required to answer questions in the intended order by selecting the matching button before being allowed to advance to the next question in order to prevent non-response (Evans \& Mathur, 2005). The backend of the web survey consisted of an Excel spreadsheet that automatically tabulated responses, facilitating the efficient management and analysis of the data (Dey, 1993) and ensuring respondent anonymity.

With regard to the semi-structured interviews with identified talented company employees the composition of each question was guided by the literature pertaining to the retention of top talent in the workplace (refer to Appendix 2). This process ensured the systematic capturing of the information.

\section{Data analysis}

Drawing on the Excel spreadsheet that captured respondents' answers, the results were tabulated into specific categories and descriptive statistics were extracted. The company interviews were transcribed and subjected to content analysis. This process involved the codification of the qualitative data into predefined categories in a systematic manner in order to identify themes,
TABLE 1

Respondent skill, experience levels and qualifications whilst in South Africa

\begin{tabular}{lrr}
\hline ITEM & DESCRIPTION & $\%$ \\
\hline Skills level & Executive management & 7.0 \\
& Senior management & 25.0 \\
Middle management & 21.0 \\
Supervisory & 11.0 \\
Experience level & 13.0 \\
& Business owner & 23.0 \\
& Less than 15 years & 23.0 \\
& $15-20$ years & 42.0 \\
Qualification & $21-25$ years & 19.0 \\
$26-30$ years & 12.0 \\
30 years+ & 4.0 \\
& Matric & 20.0 \\
& Tertiary qualification & 52.0 \\
(excl. degree) & 13.0 \\
Honours degree & 7.0 \\
Masters degree & 8.0 \\
\hline
\end{tabular}

concepts and meanings (Burns, 2000); the defined categories of classification resulted in the data either belonging to a category or not (Guthrie \& Parker, 1990). This approach also assumed that frequency indicated the importance of the subject matter (Krippendorff, 1980). The systematic themes that emerged were grouped together to establish the main factors that would retain talented employees in the organisation or that would contribute to their resignation.

\section{Strategies employed to ensure quality data}

A pilot test was conducted prior to the web-based survey going live to ensure that problematic technical issues were addressed. The survey was completed as an HTML document that was checked through five browsers that utilised different platforms. The script on the HTML document was tested to ensure that the buttons corresponded with the intended statements as well as to ensure that the selected data were recorded after each question had been completed (Fox et al., 2003).

The interview guide was piloted with six interviewees at one of the selected financial institutions who did not comprise the research sample. This led to the rephrasing of one question. During the interviewing process, the researchers kept accurate notes as a means of reflecting on judgements relating to content of the interviews.

\section{Reporting}

The findings in this paper are reported in tabular format along with qualitative commentary.

TABLE 2

Dates of emigration

\begin{tabular}{|c|c|c|c|c|c|c|c|}
\hline \multirow{2}{*}{$\begin{array}{l}\text { DATE OF } \\
\text { EMIGRATION }\end{array}$} & \multicolumn{5}{|c|}{ RACE } & \multicolumn{2}{|c|}{ GENDER } \\
\hline & WHITE & AFRICAN & INDIAN & COLOURED & TOTAL & MALE & FEMALE \\
\hline 2006 & 21 & 0 & 0 & 0 & 21 & 9 & 12 \\
\hline 2005 & 12 & 0 & 0 & 0 & 12 & 8 & 4 \\
\hline 2004 & 2 & 0 & 0 & 0 & 2 & 1 & 1 \\
\hline 2003 & 8 & 0 & 0 & 0 & 8 & 5 & 3 \\
\hline 2002 & 5 & 0 & 0 & 3 & 8 & 5 & 3 \\
\hline 2001 & 8 & 0 & 0 & 1 & 9 & 5 & 4 \\
\hline 1994-2000 & 20 & 0 & 0 & 0 & 20 & 12 & 8 \\
\hline Prior to 1994 & 2 & 1 & 1 & 0 & 4 & 2 & 2 \\
\hline TOTAL & 78 & 1 & 1 & 4 & 84 & 47 & 37 \\
\hline
\end{tabular}


TABLE 3

Factors driving emigration: Web survey respondents

\begin{tabular}{|c|c|c|c|}
\hline \multirow[t]{2}{*}{ DATE OF EMIGRATION } & \multirow{2}{*}{$\begin{array}{l}\text { REASONS FOR } \\
\text { EMIGRATION }\end{array}$} & \multicolumn{2}{|c|}{ RESPONSES } \\
\hline & & $(\mathrm{N}=84)$ & $\%$ \\
\hline Prior to 1994 & $\begin{array}{l}\text { Uncertainty about } \\
\text { South Africa's future }\end{array}$ & 4 & 4.8 \\
\hline \multirow[t]{2}{*}{$1994-2000$} & $\begin{array}{l}\text { Job insecurity \& no } \\
\text { future for children }\end{array}$ & 18 & 21.4 \\
\hline & Corruption & 2 & 2.4 \\
\hline 2001-2002 & $\begin{array}{l}\text { Increase in violent } \\
\text { crime \& job insecurity }\end{array}$ & 17 & 20.2 \\
\hline 2003-2004 & $\begin{array}{l}\text { Increase in violent } \\
\text { crime \& job insecurity }\end{array}$ & 10 & 12.0 \\
\hline 2005-2006 & $\begin{array}{l}\text { Increase in violent } \\
\text { crime \& job insecurity }\end{array}$ & 33 & 39.3 \\
\hline
\end{tabular}

\section{RESULTS}

The respondents to the web-based survey were noted to be entrepreneurs, were skilled and had extensive work experience. $23 \%$ reported that they previously owned their own businesses while the remaining $77 \%$ all occupied management positions in South Africa prior to emigration. $80 \%$ of the respondents claimed to have some tertiary qualification or honours, masters or doctoral degree and $77 \%$ reported having over 15 years of work experience. While $52 \%$ of respondents stated that they had a tertiary qualification but no degree, such tertiary qualification, along with the substantiating statistics of the quality of South African emigrants to New Zealand (Merwood, 2008), appears to indicate that respondents can be regarded as talented South Africans. These findings are summarised in Table 1.

$70 \%$ of respondents reported remaining in the same professions that they occupied whilst working in South Africa, such as accounting, banking, engineering, information technology, education and nursing upon emigrating to New Zealand. 62\% of the respondents stated that they did not intend to return to South Africa. The remainder stipulated that their decision to return would be based on whether or not crime and corruption were addressed as well as on job opportunities being available for white South Africans.

An association exists between the socio-political factors operating in South Africa and the number of respondents who emigrated during specific times, as summarised in Table 2.

From Table 2, it can be seen that white people constituted the main group of émigrés in the sample and that there has been a recent increase in emigration to New Zealand, with 33 respondents (39.3\%) departing during 2005-2006.

From Table 3, it can be seen that the dominant reasons furnished by these respondents for emigrating were job insecurity and an increase in crime.

27 respondents (32.1\%) emigrated during 2001-2004 (see Table 2 ), the overwhelming reasons also being the increase in crime and job insecurity (see Table 3). Between 1994 and 2000, 20 respondents $(23.8 \%)$ emigrated during this seven-year period of political transition in South Africa (see Table 2). For these 20 respondents, the predominant reason cited for emigrating was also job insecurity, but, in addition, concern about a future for children in South Africa was expressed (see Table 3). Four respondents stated that they emigrated prior to 1994 due to uncertainty about South Africa's future.

With reference to the semi-structured interviews, while the questions were adhered to, the open-ended nature of such questions resulted in information being gained that was sometimes broader than was anticipated. All interviewees noted that in the quest to become global players, their organisations had undergone restructuring, including the introduction of new leadership and the shift in emphasis to human resources as well as the bottom line. However, within these parameters, interviewees criticised their organisations for still being somewhat bureaucratic and hierarchical, with a tolerance, in some instances, for mediocre performance.

While executive leadership was noted to communicate business growth strategy, all interviewees stated that their organisations' leaders were perceived to be removed from the coalface and part of an exclusive 'old boys' club'. They regarded this exclusionary behaviour relating to the 'old boys' club' as preventing transparent succession planning and promoting existing hierarchical structures. $80 \%$ of the interviewees noted that the layers of authority in the organisations that had been created over the years retarded entrepreneurship and they expressed frustration at how such structures facilitated mediocrity and slowed the growth of a high-performance culture.

The interviewees unanimously stated their support for company compliance with employment equity as a means of securing business. The focus of employment equity, noted by interviewees, was on the legal compliance of business as a necessity to survive in the marketplace. No mention was made by any interviewee of the benefits of a diversified workforce for local and global competitiveness. However, $80 \%$ of the white male interviewees expressed frustration at the possibility of limited future career growth due to employment equity and a fear of being replaced by someone from an historically disadvantaged background. Half of the group of white interviewees expressed a reluctance to train, develop and mentor previously disadvantaged employees due to this fear. All the white male interviewees and $40 \%$ of the white female interviewees stated the need for a termination date to be placed on the affirmative action component of employment equity as they felt that it was unfair that race instead of merit is used as a determinant of development. It was mentioned that the sentiments harboured about employment equity and the related uncertainty regarding career progression could lead to a lack of trust and engagement between black and white colleagues. In contrast, all black interviewees highlighted the slow rate at which employment equity was occurring throughout their organisations. $90 \%$ of the white female respondents indicated that excessive emphasis was placed on affirmative action (primarily benefiting males), leading to an overall underrepresentation of women in senior leadership positions.

The majority of interviewees indicated that a strong allegiance to their employers' brand, the high-performance culture in their top talent groups and the well-structured leadership development programmes provided to them were factors that contribute to their retention. They also regarded the support and guidance from their mentors as being invaluable to their growth as well as being a critical tool in retaining them.

The responses of the interviewees have been summarised into the themes according to their implications for talent attraction, retention or attrition. The majority sentiments have been later indicated in Figure 1.

With regard to what attracted interviewees to their current employers, four common themes emerged from all the interviewees:

- Quality and depth of company leadership development programmes, including personal growth and development opportunities

- High-performance workplace cultures that offer challenging and stimulating work opportunities

- Attractive company brand and a culture that actively promotes people development and is ethical in its business approach

- Competitive remuneration packages.

The four main themes that emerged, sometimes articulated more strongly by a particular group, as reasons for considering alternative employment are as follows: 


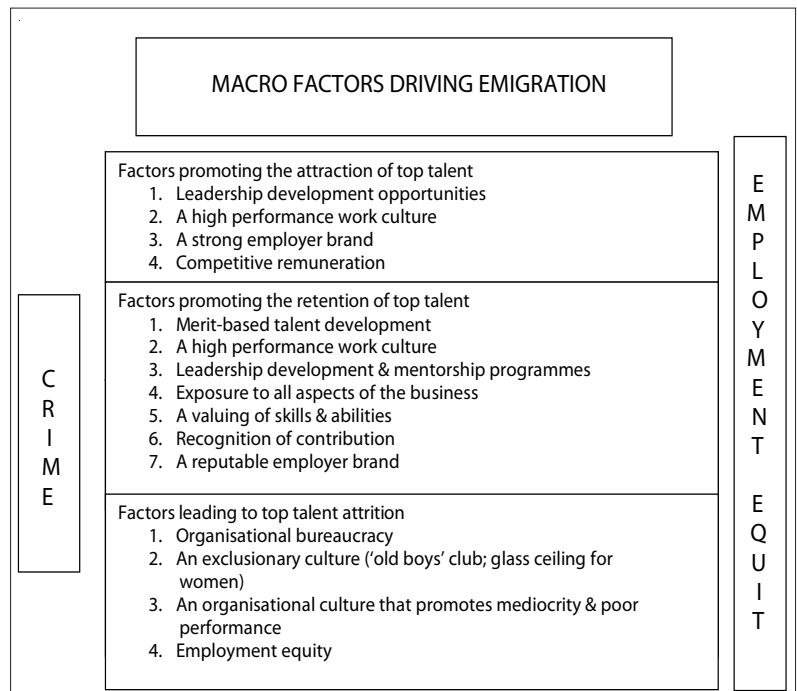

UNCERTAINTY OF FUTURE OF COUNTRY

FIGURE 1

Factors influencing talent attraction, attrition, retention and emigration

- Levels of organisational bureaucracy that stunt an entrepreneurial mindset ( $80 \%$ of interviewees)

- A senior leadership level dominated by an old boys' club mentality in which new leaders are invited to join based on internal, exclusionary networking (40\% of interviewees, primarily females); a work culture in which women are not recognised and promoted into leadership roles (90\% of white female interviewees and the one black female interviewee)

- An organisational culture that allows for mediocrity and poor performers to prevail, stunting progress in the organisation (100\% of interviewees)

- Limited career opportunities due to affirmative action ( $80 \%$ of white male interviewees; $90 \%$ of white female interviewees).

The following seven factors were regarded as critical to retention:

- Development according to merit and not race $(80 \%$ of white male interviewees)

- Being part of a high-performance work culture in which mediocrity and poor performers are not tolerated $(100 \%$ across all groups)

- Personal growth associated with participating in leadership development programmes, including an international sabbatical at a Centre of Excellence $(100 \%$ of black interviewees; $80 \%$ of white interviewees), and being part of a mentorship programme conducted by senior leaders who offer guidance on career progression $(100 \%$ of black interviewees; $50 \%$ of white interviewees)

- Being exposed to all aspects of the business (100\% of black interviewees; $70 \%$ of white interviewees)

- Being valued for skills and ability $(60 \%$ of white interviewees)

- Being recognised for contribution to the organisation $(100 \%$ of black interviewees; $60 \%$ of white interviewees)

- Being employed by an organisation with a respected employer brand (100\% of black interviewees; $60 \%$ of white interviewees).

Black and white interviewees expressed differences in opinion on this topic. None of the black interviewees saw any reason to emigrate. They viewed this period of transition in South Africa as an exciting time of transformation and considered any brain drain to be inevitable in a global marketplace. These interviewees also noted that they would consider an international assignment that would benefit career growth but would feel obliged to return to South Africa to transfer their acquired skills. Of the white interviewees, $70 \%$ cited crime, safety concerns for their families, affirmative action and uncertainty of the country's future as reasons why South African talent would consider emigration. $30 \%$ cited concern primarily about the future of their children in terms of safety and ability to obtain employment. The above findings are illustrated in Figure 1.

\section{DISCUSSION}

The objective of the study was to explore some of the reasons for the emigration of talent in South Africa and to identify reasons for talent attrition at senior levels in organisations in order to understand what can be done to retain talent in the country as well as to provide business leaders with insight into strategies that can be used to retain the top talent that remains in the country, currently employed in South African organisations. In this manner, it is endeavoured to provide practical guidance for strategy development as one means of addressing the skills and talent shortage in the country.

\section{Macro drivers of talent loss}

From the findings of the web survey (see Table 3), it can be seen that specific macro social, economic and political factors in South Africa directly influence the reasons for emigration. The two waves of emigration appear to have been during 1994-2000 (when the ANC government came into power) and during 20052006 (when a strong focus on transformation in South Africa including on employment equity in the workplace, was evident). Most émigrés were white South Africans, reflecting national emigration statistics (Statistics South Africa, 2005).

With regard to reasons for emigrating, similarities are reported by web survey respondents and interviewees, with $70 \%$ of the white interviewees identifying the same macro driving forces of crime and personal safety. Similarly, $80 \%$ of the white males cited affirmative action as a reason to emigrate and $30 \%$ of the white females cited concerns for the safety and future of their families as a reason for emigration.

Those who emigrated from South Africa appear to have moved into similar senior or entrepreneurial jobs in New Zealand, reinforcing the view that the loss of talent has economic implications for a country (Birt et al., 2004). This is all the more a cause for concern given the seeming increase in emigration by talented South Africans during 2005-2006 and the awareness of the possibility of emigration by the top achievers interviewed.

\section{Micro drivers of talent attraction, retention and loss}

All the interviewees reported the challenges of transformation and globalisation faced by their organisations. The interviewees reported that, in line with striving to be competitive, their organisations were focusing upon both human resources and bottom-line profitability, coupled with the development of high-performance work cultures, a trend also articulated by Crosbie (2005), Luna-Arocas and Camps (2008) and Maxwell and Farquharson (2008). According to Rudy Giuliani, the former mayor of New York, 'the only way to lure and retain bright, energetic self-starters is to create an environment that allows them to shine' (Lockhead, 2005, p. 9).

A strong work culture, coupled with leadership development opportunities, a strong employer brand along with the associated values and competitive remuneration were noted to be factors that attracted the top achievers to their companies or factors that would attract them to other companies (Houkes et al., 2003; Iverson \& Roy, 1994). According to Glen (2006), organisations with a solid strategy for developing an employer brand will be an attractive force for both external and internal top talent.

Similar factors promoting the attraction of top talent are amongst those reported to promote their retention, viz a 
high-performance work culture, leadership development and mentoring programmes with exposure to all aspects of the business and a strong employer brand. A well-structured leadership development programme was noted to provide organisations with a competitive edge, particularly when an international sabbatical is offered, with exposure to all aspects of the business. This finding is supported by Brocksmith (1997) and Glen (2006), who state that high-potential employees seek opportunities to rapidly develop their careers and enhance their marketability.

It is interesting to note that while a competitive remuneration package was noted by all interviewees as a factor that would attract them to an organisation, it was not mentioned by any as a factor that would promote their retention. In contrast, it appears that once top achievers join an organisation, they then also require a valuing of their skills and abilities and a recognition of the contribution that they are making.

Organisational culture appears to be an important factor in attracting and retaining top achievers as well as in their attrition. A high-performance work culture with little organisational bureaucracy was clearly articulated as a reason for the attraction and retention of top achievers. This theme was enlarged upon when top talent attrition was discussed, where comment centred on the problem of exclusionary cultures, 'old boys' networks' and the lack of senior women in organisations. These three practices could be considered to promote a culture that does not reward high work performance but rather rewards people according to their inclusion in informal networks (e.g. the old boys' club) and gender, as noted by Coulson-Thomas (1994).

All interviewees agreed that organisations must comply with employment equity legislation in order to secure business. However, the majority of the white male interviewees submitted that the implementation of employment equity in the workplace was a contributing factor in the loss of critical skills. The majority of white male interviewees also noted that development should be based on merit and not race. It is interesting to note that these sentiments reflect those of the primarily white émigrés in the sample who left South Africa during 1994-2006.

Of concern are the different views of the black and white interviewees concerning employment equity. While white interviewees (especially males) were concerned about its impact on future career prospects, black interviewees appeared to consider this aspect of organisational transformation as progressing too slowly. Latent discontent can arise because of the harbouring of hostile feelings about employment equity or anger about slow progress. An earlier South African study (Thomas, 2003) of the progress of employment equity in South African companies noted the tensions between black and white employees and the opposing views and expectations held. Horwitz (1996) states that a failure to understand such differences can lead to misguided assumptions, poor working relations, underperformance and discrimination. Glen (2006) emphasises the need for these 'hot' buttons to be managed in order to ensure retention, engagement and motivation of key employees. Uys (2003) highlights the effects of affirmative action on white employees, viz. low productivity, resignations, depression, emigration and even suicide.

None of the interviewees mentioned, other than for legal compliance, the benefits derived from having a diversified workplace to drive the future sustainability of the business. What is apparent is that both of these financial institutions are adhering to the principles of affirmative action for employee attraction and retention reasons. What appears not to be filtered down to employees is the benefit and purpose of a diversified workplace culture. The value of a diversified workforce and the competitive advantage that it affords have been well documented and include creativity and problem solving (Thomas \& Ely, 1996), enhanced strategic decision making (Watson, Kumar
\& Michaelsen, 1993) and understanding diverse markets and customers, suppliers and distributors (Thomas \& Ely, 1996). According to Tung (1995), the goal of valuing diversity is about drawing on the strengths of the individual or subgroup to ensure that the whole is greater than the sum of its parts.

With regard to talent retention, Jenner (1994, p. 12) argues that effectively managing the mix of employee diversity, in this case at senior levels where top talent resides, assists organisations in becoming workplaces of choice and being able to 'pick from the ever shrinking pool of highly skilled employees'. Yu (2002) and Robinson and Harvey (2008) highlight that addressing this challenge requires a strategic effort on the part of leaders.

\section{Recommendations}

The findings of the web survey indicate that the following macro driving forces of talent emigration should be addressed: violent crime, personal safety and employment opportunities. Certain respondents indicated that should these macro factors be addressed, they might consider returning to South Africa. These same macro factors were noted by the company interviewees, although white interviewees were more concerned than black interviewees about future career prospects; black interviewees also expressed an acceptance of the brain drain in a global marketplace.

Common factors identified with regard to talent retention in companies include leadership development programmes, a highperformance work culture that promotes development, a strong employer brand and a competitive remuneration package. A major driver of top talent turnover was noted to be a bureaucratic structure, a workplace culture that tolerates poor performers, the existence of an old boys' club, an exclusionary workplace culture and the impact of affirmative action on career prospects (the latter being raised as a problem primarily by white male interviewees). No mention was made by any of the interviewees of the value of a diverse workforce and no recognition was given to the positive effects of a diversified workforce on the overall sustainability of an organisation.

From the findings of the web-based survey and the interviews, specific recommendations can be made to government with regard to the addressing of the brain drain, these being that governmentaddress the prevailing violent crime, that the personal safety of citizens be guaranteed within normal parameters and that whites not be excluded indefinitely from competing for work opportunities. In this regard, it is acknowledged that the country must address historical imbalances due to the policy and practices of apartheid. However, active research should be undertaken with regard to the changes that have been achieved since the implementation of the Employment Equity Act (Republic of South Africa, 1998), and such feedback should determine a timeline, if necessary, for the slackening of the targeted demographic requirements of the legislation. It is imperative that government addresses these macro drivers of emigration to ward off the continued loss of talent.

Top talent interviewees highlighted that both organisations were undergoing transformation that was impacting upon all aspects of the business. According to Hughes (1996), for any successful organisational transformation to occur, the alignment, buyin, involvement and participation of all employees are vital. Attitudinal and behavioural changes are essential to ensuring sustained performance.

Accordingly, for business to retain top talent, the following is recommended:

- Business leaders must consciously develop a culture of transformation in their organisations. Such transformation must include expectations of high standards, competitive remuneration packages, leadership development and an inclusive culture that actively embraces employee diversity, including that brought in by white males. Denton and Vloeberghs (2003) note that this action could reduce the 
fear of white employees of being replaced and future career uncertainty, allowing for individual commitment to organisational change and transformation. In this process, the fear often expressed by black employees of lack of progress in transformation will also be addressed. Diversity in the workplace needs to be embraced as a tool that can promote organisational strategy and competitiveness (Robinson \& Harvey, 2008).

- Leadership must openly address the underlying employee tensions and fears associated with the implementation of employment equity. It is not enough to adhere to legislation that aims at addressing past discrimination without addressing the impact of the associated change in the workplace. In order to tackle this fear, business leaders need to instil a workplace culture in which mentorship and knowledge sharing are rewarded. Meyer and Allen (1997) support this notion by stating that commitment from employees is developed when an organisation conveys a supportive environment in which individual contribution is valued, resulting in a fulfilling work experience. This in turn creates an environment in which individuals are empowered and their expertise trusted, thus obviating the need for bureaucratic layers of checks and balances that currently frustrate the top talented employees.

- The business reasons for diversity should be fully debated in organisations so that employees are enabled to move to a position of 'integration and learning' as advocated by Ely and Thomas (2001, p. 242), who state that the competitive advantage of a diverse work force 'lies in the capacity of its members to learn from each other and develop in each other a range of cultural competencies that they can all then bring to bear on their work'. These authors advocate that adherence to this paradigm is related to sustainable organisational performance.

\section{Limitations}

The following limitations of the study that impact on the generalising of the findings are noted:

- Despite the web surveys being advertised on eight expatriate South African websites, it was essentially open to the public and therefore it cannot be guaranteed that all respondents were South African expatriates. In the absence of filters to screen out non-expatriates and those expatriates not in employment, the possibility cannot be excluded that this omission contaminated the findings. However, the structuring of the questions attempted to control this limitation to some extent.

- The web survey restricts the sample to Internet users, resulting in the exclusion of potential respondents.

- The validity of web-based surveys has been criticised due to coverage problems and sampling error (Manfreda \& Vehovar, 2002).

- The questionnaire posted on the websites was not tested for validity or reliability.

- Both the number of web-based respondents and interviewees were small and responses may not be representative of broader populations.

- The number of black interviewees was small and therefore the views expressed are mainly those of white interviewees.

- Interviewer bias and assumptions may have impacted the interview process and the interpretation of responses.

- The interviews were conducted in one industry in South Africa and may have highlighted issues that are unique to this industry.

\section{Suggestions for further research}

Given the need to enhance the competitiveness of South African business, there is a need for government and business to find solutions that will enhance top talent retention. It is therefore recommended that the following areas of future research be considered:

- Measuring the turnover intentions of top achievers in a range of South African businesses and attempting to correlate this with perceptions of some of the macro factors identified in this study (crime, violence, employment equity and job insecurity) and with some of the micro factors identified (organisational culture and development) with the aim of attempting to predict factors leading to talent loss

- Employing a larger sample, drawn through stratified random sampling, to correlate perceptions of push and pull factors relating to talent loss with demographics, for example age, race, gender and tenure with the organisation

- Quantifying the impact of the brain drain on South African business to guide staff development and leadership planning

- Extending the present research to a broader range of industries, which may highlight similar or additional areas to be considered in talent attraction and retention

- Building and testing a talent retention model for South African organisations that could include addressing white male career fears, devising the appropriate developmental processes including mentoring and knowledge sharing, developing an organisational culture that is fully inclusive of diversity and articulating high work standards

- Exploring the impact of transformational leadership and core leadership competencies on the retention of top talent.

\section{Conclusion}

In conclusion, the present study merely touched on the issue of talent retention in South Africa. For the country to become globally competitive, it is essential that this topic be actively pursued by academics and business practitioners alike, with the aims of developing strategies to retain talent in the country nurturing and developing the talent that remains in South African organisations.

\section{REFERENCES}

Behar, A. (2006). ASGISA and JIPSA: Will those who remain unskilled also get to share? Paper presented at the Accelerated and Shared Growth Conference in South Africa: Determinants, Constraints and Opportunities, Johannesburg, Gauteng.

Birt, M., Wallis, T., \& Winternitz. G. (2004). Talent retention in a changing workplace: An investigation of variables considered important to South African talent. South African Journal of Business Management, 35(2), 25-31.

Brocksmith, J.G. (1997). Passing the baton: Preparing tomorrow's leaders. In F. Hesselbein, M. Goldsmith \& R. Beckhard (Eds.), The organization of the future, (pp. 251-258). San Francisco: Jossey-Bass.

Burns, R. (2000). Introduction to research methods. New Delhi: Sage Publications.

Clarke, K. (2001). What businesses are doing to attract and retain employees: Becoming an employer of choice. Employee Benefits Journal, 26(1), 21-24.

Contogiannis, T. (2007). Economic growth, constraints and prospects for the South African economy. Discourse, 35(2), 38-44.

Coulson-Thomas, C. (1994). Developing directors: Building an effective boardroom. Journal of European Industrial Training, 186, 29-52.

Crosbie, R. (2005). Learning the soft skills of leadership. Industrial and Commercial Training, 37(1), 45-51.

Crush, J. (2002). The global raiders: Nationalism, globalisation and the South African brain drain. Journal of International Affairs, 56(1), 147-172.

Denton, M., \& Vloeberghs, D. (2003). Leadership challenges for organizations in the new South Africa. Leadership and Organization Development Journal, 24(2), 84-95.

Dey, I. (1993). Qualitative data analysis: A user-friendly guide for social scientists. London: Routledge.

Du Preez, J. (2002). The depletion of the human resources pool in South Africa. Acta Commercii, 2, 80-84

Elangovan, A.R. (2001). Causal ordering of stress, satisfaction and commitment, and intention to quit: A structural equations analysis. Leadership and Organization Development Journal, 22(4), 159-165. 
Ely, R.J., \& Thomas, D.A. (2001). Cultural diversity at work: The effects of diversity perspectives on work group processes and outcomes. Administrative Science Quarterly, 46, 229-273.

Evans, J., \& Mathur, A. (2005). The value of online surveys. Emerald Internet Research, 15(2), 195-219.

Finestone, N., \& Snyman, R. (2005). Corporate South Africa: Making multicultural knowledge sharing work. Journal of Knowledge Management, 9(3), 128-141.

Fox, J., Murray, C., \& Warm, A. (2003). Conducting research using web-based questionnaires: Practical, methodological and ethical considerations. International Journal of Social Research Methodology, 6(2), 167-180.

Gbadamosi, G. (2003). HRM and the commitment rhetoric: Challenges for Africa. Management Decision, 41(2), 274-280.

Glen, C. (2006). Key skills retention and motivation: The war for talent still rages and retention is the high ground. Industrial and Commercial Training, 38(1), 37-45.

Griffeth, R.W., Hom, P.W., \& Gaertner, S. (2000). A meta-analysis of antecedents and correlates of employee turnover: Update, moderator tests, and research implications for the millennium. Journal of Management, 26, 463-488.

Gubrium, J., \& Holstein, J. (1997). The new language of qualitative method. New York: Oxford University Press.

Guthridge, M., Komm, A.B., \& Lawson, E. (2008). Making talent a strategic priority. The McKinsey Quarterly, 1, 49-59.

Guthrie, J., \& Parker, L.D. (1990). Corporate social disclosure practice: A comparative international analysis. Advances in Public Interest Accounting, 3, 159-175.

Horwitz, F. (1996). Human resource development and managing diversity in South Africa. International Journal of Manpower, 17(4/5), 134-151.

Houkes, I., Janssen, P.P.M., De Jonge, J., \& Bakker, A.B. (2003). Specific determinants of intrinsic work motivation, emotional exhaustion and turnover intention: A multisample longitudinal study. Journal of Occupational and Organizational Psychology, 76, 427-450.

Hughes, M. (1996). Indaba on quality: A South African challenge overcome. Managing Service Quality, 6(3), 23-26.

IMD. (2008). Word competitiveness yearbook. Retrieved November 18, 2008, from http://www.worldcompetitiveness.com.

Iverson, R.D., \& Roy, P. (1994). A causal model of behavioral commitment: Evidence from a study of Australian bluecollar employees. Journal of Management, 20, 15-41.

Jackson, W., Alessandri, T., \& Black, S. (2005). The price of corporate social responsibility: The case of Black Economic Empowerment transactions in South Africa. Atlanta: Federal Reserve Bank, Working Paper Series.

Jenner, L. (1994). Diversity management: What does it mean? HR Focus, 71(1), 11.

Kim, S.W., Price, J.L., Mueller, C.W., \& Watson, T.W. (1996). The determinants of career intent among physicians at a U.S. Air Force hospital. Human Relations, 49, 947-976.

Krippendorff, K. (1980). Content analysis: An introduction to its methodology. Beverly Hills: Sage Publications.

Lengahan, J.A., \& Eisner, A.B. (2006). Employers of choice and competitive advantage: The proof of the pudding is in the eating. Journal of Organizational Culture, Communication and Conflict, 10(1), 99-109.

Lockhead, E. (2005). The COI path to HR success: Three key steps to award-winning performance. Human Resources Management International Digest, 13(7), 9-10.

Lum, L., Kervin, J., Clark, K., Reid, F., \& Sirola, W. (1998). Explaining nursing turnover intent: Job satisfaction, pay satisfaction or organizational commitment? Journal of Organizational Behavior, 19(3), 305-320.

Luna-Arocas, R., \& Camps, J. (2008). A model of high performance work practices and turnover intentions. Personnel Review, 37(1), 26-46.

Luthans, F., Van Wyk, R., \& Walumbwa, F. (2004). Recognition and development of hope for South African organisational leaders. The Leadership and Organisational Development Journal, 25(6), 512-527.
Mallol, C.M., Holtom, B.C., \& Lee, T.W. (2007). Job embeddedness in a culturally diverse environment. Journal of Business Psychology, 22, 35-44.

Manfreda, K.L., \& Vehovar, V. (2002). Survey design features influencing response rates in web surveys. Retrieved December 20, 2007, from http://www.icis.dk/ICIS_papers/C2._4_3. pdf.

Maxwell, G., \& Farquharson, L. (2008). Senior managers' perceptions of the practice of human resource management. Employee Relations, 30(3), 304-322.

Merwood, P. (2008). Migration trends 2006-2007. New Zealand Department of Labour. Retrieved April 18, 2009, from http://www.immigration.govt.nz/research

Meyer, J.P., \& Allen, N.J. (1997). Commitment in the workplace: Theory, research and application. London: Sage Publications.

Mitchell, J. (2003). A new review about the white exodus from South Africa. Retrieved December 20, 2007, from http://www. SouthAfricaEmigration.com/reviews.htm

Mitchell, T.R., Holtom, B.C., \& Lee, T.W. (2001). The development of an effective employee retention plan. Academy of Management Executive, 15(4), 96-108.

Mueller, C.W., Boyer, E.M., Price, J.L., \& Iverson, R.D. (1994). Employee attachment and noncoercive conditions of work: The case of dental hygienists. Work and Occupations, 21, 179-212.

Oberoi, S., \& Lin, V. (2006). Brain drain of doctors from southern Africa: Brain gain for Australia. Australian Health Review, 30(1), 25-33.

Paton, C. (2003, 20 June). Artisan alert. Financial Mail, p. 18.

Pfeffer, J. (1994). Competitive advantage of people: Unleashing the power of the work force. Boston: Harvard Business School Press.

Prime, N. (1999). Cross-cultural management in South Africa: Problems, obstacles and solutions in companies. Retrieved December 20, 2007, from http://www.marketing.byu.edu.

Ratcliffe, J. (2002). Scenario planning: Strategic interviewing and conversations. Foresight, 4, 19-30.

Republic of South Africa. (1998). The Employment Equity Act, Act 55 of 1998. Pretoria: Government Printers.

Republic of South Africa. (2003). The Broad-based Black Economic Empowerment Act, Act 53 of 2003. Pretoria, South Africa: Government Printers.

Robinson, D.A., \& Harvey, M. (2008). Global leadership in a culturally diverse world. Management Decision, 46(3), 466480.

Roodt, A. (1997). In search of a South African corporate culture. Management Today, 13(2), 14-16.

Schaufeli, W.B., \& Enzmann, D. (1998). The burnt out companion to study and practice: A critical analysis. London: Taylor \& Francis.

Simelane, S. (1999, July). Trends in international migration among professionals, semi-professionals and miners in South Africa, 1970-1997. Paper presented at the Annual Conference of the Demographic Association of Southern Africa, Saldanha Bay, South Africa.

Statistics South Africa. (2005). Documented migration. Report No. 03-51-03. Retrieved December 20, 2007, from http://www. statssa.gov.za.

Thomas, A. (2002). Employment equity in South Africa: Lessons from the global school. International Journal of Manpower, 23(3), 237-256.

Thomas, A. (2003). Employment equity practices at selected companies in South Africa. South African Journal of Labour Relations, 27(3-4), 6-40.

Thomas, A., \& Doak, R. (2000). The development of shared values: Impact on employee behaviour and on customer perception of service. South African Journal of Business Management, 31(1), 17-30.

Thomas, A., \& Jain, H.C. (2004). Employment equity in Canada and South Africa: Progress and propositions. International Journal of Human Resource Management, 15(1), 35-54. 
Thomas, D.A., \& Ely, R.J. (1996). Making differences matter: A new paradigm for managing diversity. Harvard Business Review, 74(5), 79-90.

Tung, R. (1995). The global human resources challenge: Managing diversity in international settings. In Proceedings of the 10th World Congress of the International Industrial Relations Association, 31 May-4 June 1995 (pp. 16-24). Washington DC, USA.

Uys, I. (2003). Diversity management: Reasons and challenges. Politeia, 22(3), 30-48.

Watson, W.E., Kumar, K., \& Michaelsen, L.K. (1993). Cultural diversity's impact on interaction process and performance: Comparing homogeneous and diverse task groups. Academy of Management Journal, 35, 91-121.

$\mathrm{Yu}$, L. (2002). Does diversity drive productivity? Sloan Management Review, 43(2), 17.

\section{APPENDICES}

\section{APPENDIX 1}

Web survey questions

Please note that the questions included here are not formatted according to the questionnaire that was placed on the websites. The listing of the questions posed to respondents is intended to provide readers with the gist of the questions asked in the survey.

\section{Gender}

2. Race

3. Current age

4. When did you leave South Africa?

5. What was the highest qualification that you held when living in South Africa?

6. What was the main reason for emigrating to New Zealand?

7. Under what conditions would you consider returning to South Africa on a Under what condio

8. Whilst living and working in South Africa, in which industry have you gained most of your experience?

9. While you worked in South Africa, were you a permanent employee, a temporary employee, a contractor or self-employed?

10. Which of the following best described your position while working in South Africa - executive management, senior management, middle management, junior management, supervisory business owner or other (please specify)?

11. How many years of working experience did you gain in your industry whilst living in South Africa? living in South Africa?

continuing to work in the same profession/occupation in New Zealand as you did when living in South Africa? If not, please specify your new profession/occupation.

\section{APPENDIX 2}

Interview quide questions

Name of company
Respondent name (for internal use only)
Job title
Race
Gender
Length of service
Grade in company
Level of responsibility
1. What position do you occupy in the company and what does it involve?
2. What attracted you to seek employment at your current employer?
3. Please describe your career plan as discussed between you and
4. Whagement. What do you think that a company should do to retain its top achievers?
5. If an opportunity arose with another company, what would you investigate
6. What do you think your company regards as important in terms of its
people?
7. If you could change or improve upon certain aspects of your company's work
8. What advice would you give to executive management if you had to make
suggestions about how the company can retain its top talent?
9. What do you think are the main reasons why top achievers leave their
organisations?
10. South Africa is said to be experiencing a brain drain of its top talent due to
emigration. What would make you decide to take up an opportunity outside
of South Africa?

